\title{
Long-Term Dependencies of Annual and Semiannual Components of NmF2 Over Concepción
}

\author{
Manuel A. Bravo, Alberto J. Foppiano* and Rodrigo Abarca del Río
}

\author{
Departamento de Geofísica, Facultad de Ciencias Físicas y Matemáticas, Universidad de Concepción, Avda. Esteban \\ Iturra s/n, Barrio Universitario, Concepción, Chile
}

\begin{abstract}
In this work an attempt is made to determine whether the annual and semiannual components of the NmF2 observed over Concepción $\left(36.8^{\circ} \mathrm{S} ; 73.0^{\circ} \mathrm{W}\right)$, Chile, exhibit long-term trends. Monthly median hourly values of $\mathrm{NmF} 2$ determined from ionosonde observations are analyzed. Although the assessed trends for NmF2 and for the semiannual and annual components of $\mathrm{NmF}$, are hardly significant by any statistical test, they exhibit a systematic diurnal evolution. $\mathrm{NmF} 2$ trends are almost null during night time and negative from around noon to the early evening. The same can be said for trends of the amplitudes of the semiannual component. On the contrary, trends for the annual component are always positive and exhibit a rather irregular diurnal pattern. It seems reasonable then to particularly look for an explanation of the semiannual component long-term changes when concerned with long-term changes of NmF2. The semiannual variation is linked to composition and thermospheric wind effects, and solar zenith angle changes which may be connected to changes of the strength of the global circulation. But, more study is needed to envisage the changes on the semiannual component of NmF2 which may arise from eventual long-term changes of the global circulation.
\end{abstract}

Keywords: Long-term trends, ionosphere, NmF2, annual variation, semiannual variation.

\section{INTRODUCTION}

Although the occurrence of long-term changes and trends in the troposphere and stratosphere has been discussed for several decades, the occurrence of similar changes in the mesosphere and thermosphere -and the embedded ionosphere- has been considered only more recently, probably as a straightforward extension of lower atmosphere studies. These studies suggested that a concurrent mesosphere thermosphere "greenhouse cooling" to the lower atmosphere "greenhouse warming" should be expected [1-4], and that upper atmosphere long-term changes and trends would be associated with this cooling.

Three recent special issues of well- known journals, with reports from the same number of international meetings, attest for the vigorous research activity on the subject over the last two years [5-7].

Of particular interest is the occurrence of ionosphere Fregion long-term changes. This is because a consistent world-wide pattern of trends has yet to emerge and because this eventual pattern should be also consistent with upper atmosphere long-term changes and with what is reasonably known for the lower atmosphere [8]. Most F2-layer trend studies relate to long-term changes of the layer maximum electron concentration $(\mathrm{NmF} 2$, or the layer critical frequency foF2) and the height at which this concentration occurs (hmF2). Moreover, these changes have been generally associated with changes of greenhouse gases, the long-term variations of geomagnetic activity and secular changes of the

*Address correspondence to this author at the Departamento de Geofísica, Facultad de Ciencias Físicas y Matemáticas, Universidad de Concepción, Avda. Esteban Iturra s/n, Barrio Universitario, Concepción, Chile; Tel: $+56-$ 41-2204136; Fax: +56-41-2220104; E-mail: foppiano@udec.cl
Earth's magnetic field (review by Lastovicka [8] and references within).

On the other hand, short-term changes of the F2-layer have been known for many years (e.g. [9]). In particular, the diurnal, seasonal and annual variations of $\mathrm{NmF} 2$ observed worldwide are found not to follow the expected variations assuming direct relations to changes in solar zenith angle the so-called anomalies [10-12]. The annual and semiannual variations have been found specially interesting since no full worldwide explanation of the semiannual variation has been found, although several mechanisms have been proposed [13-16].

Here, an attempt is made to determine whether the annual and semiannual components of the $\mathrm{NmF} 2$ observed over Concepción $\left(36.8^{\circ} \mathrm{S} ; 73.0^{\circ} \mathrm{W}\right)$, Chile, exhibit long-term trends. This study is a follow- up to previous work on longterm trends of the F-region critical frequency (foF2) and $\mathrm{hmF} 2$ also for Concepción [17] and it relies on work under way on the relation of the semiannual component of $\mathrm{NmF} 2$ with thermospheric winds. It is hoped that the eventual determination of separate trends for these two components may contribute to identifying the dominant mechanism of the semiannual variation.

\section{DATA ANALYSIS}

Monthly median hourly values of $\mathrm{NmF} 2$ determined from ionosonde observations at Concepción $\left(36.8^{\circ} \mathrm{S} ; 73.0^{\circ} \mathrm{W}\right)$ are analyzed. Geophysical information is given in Table $\mathbf{1}$. Medians are for a 37- year interval covering more than three solar cycles. In a few cases interpolation was necessary to complete the data set (only three months values during 1975). Fig. (1) shows the NmF2 time series for a given hour and the corresponding wavelet spectra (http://www.pol.ac. uk/home/research/waveletcoherence/). The decadal (solar 

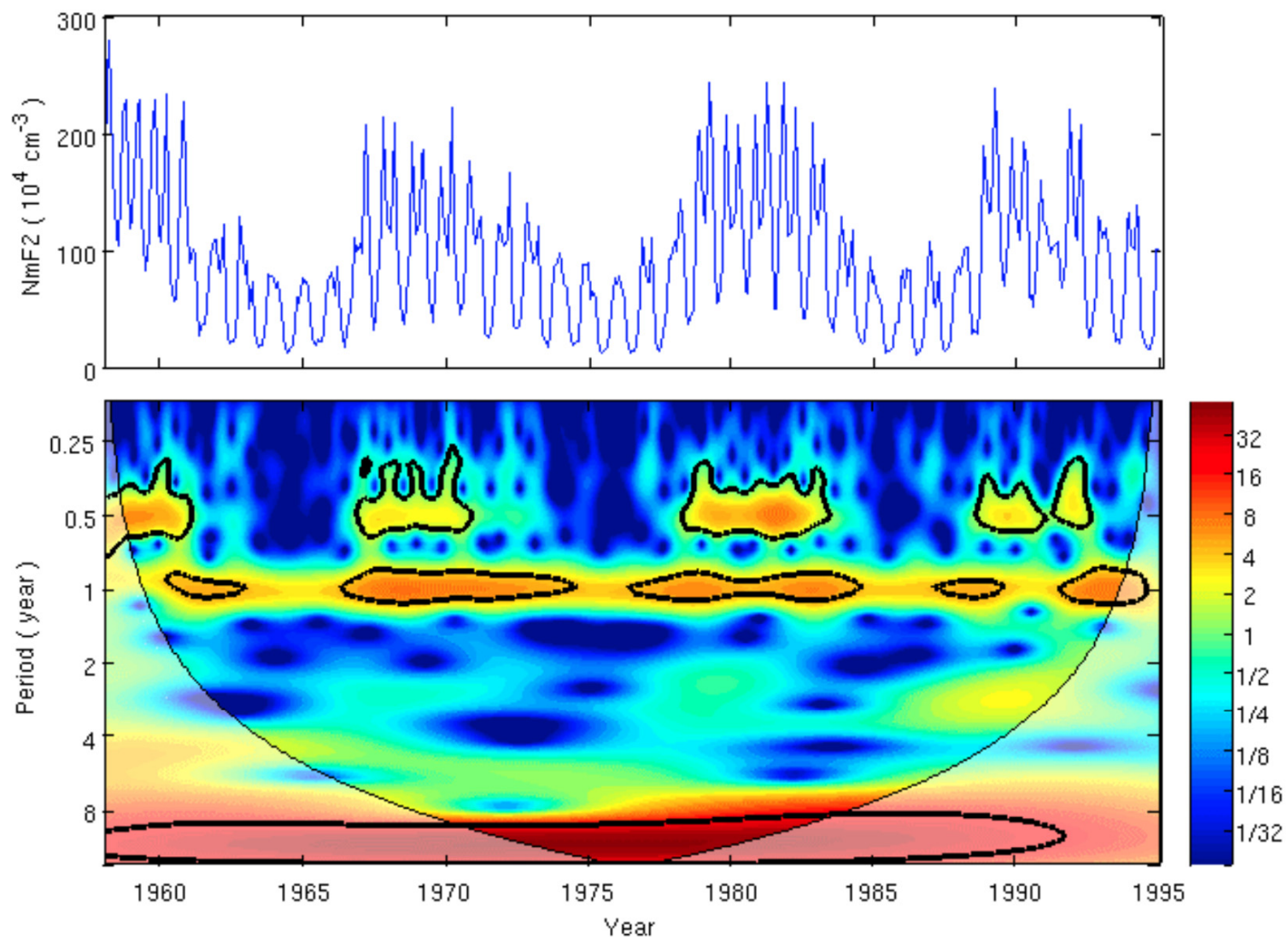

Fig. (1). Monthly median (top) $\mathrm{NmF} 2$ for Concepción $\left(36.8^{\circ} \mathrm{S} ; 73.0^{\circ} \mathrm{W}\right)$ at $18: 00 \mathrm{LT}\left(75^{\circ} \mathrm{W}\right)$ and wavelet spectra (bottom). Significant periods (thick dashed line). Spectral power (color code bar). Validity limits (thin line).

cycle), annual and semiannual contributions are clearly visible. In particular, the semiannual contribution is prominent during high solar activity.

For each hour, the annual evolutions of monthly mean $\mathrm{NmF} 2$ were Fourier analyzed to determine the amplitudes and phases of 6 components. Then NmF2 annual evolutions were reconstructed using only annual and semiannual components. Fig. (2) shows examples of the observed annual evolutions, the annual and semiannual components and the reconstructed annual evolutions. For all cases the goodness of fit of the two components model is assessed by the explained variance. The diurnal dependencies of the annual and the semiannual components are assessed by the explained variance calculated separately for each component, as well as by the amplitudes and phases of them. Fig. (3) shows examples for two years selected to cover a wide range of solar activity level. The two components model is generally very good. Although for the worst isolated case the explained variance is only $44 \%(10: 00 \mathrm{LT}, 1985)$ it relates to a small annual evolution. This enhances the little differences between model and observed values. Furthermore, for all other cases, the explained mean and median variances are $91.4 \%$ and $93.0 \%$, respectively. The model is significantly better at night and for high solar activity level. The annual component is more significant around midnight, while the semiannual is more significant around noon for high and low solar activity. The significance of the two components changes systematically with time of day.
To pursue with the trend analysis, mean values of the amplitudes and phases of the annual and semiannual components corresponding to night time (22 to $03 \mathrm{LT}$, $75^{\circ} \mathrm{W}$ ) and daytime (10 to $15 \mathrm{LT}$ ) conditions were computed for each year. Fig. (4) shows these together with yearly mean F10.7 values. The trends were then determined for amplitudes and phases of both annual and semiannual components, separately for all hours, using a simple regression analysis and also using the standard MannKendall algorithm (http://ewr.cee.vt.edu/environmental/teac $\mathrm{h} / \mathrm{smprimer} / \mathrm{sen} / \mathrm{sen} \cdot \mathrm{html} /$ ). Moreover, the dependencies of $\mathrm{NmF} 2$ and of the annual and semiannual component amplitudes of F10.7 were also determined, and the corresponding anomalies computed. Trends of these computed anomalies were determined as well.

\section{RESULTS}

Fig. (5) shows sample trends for anomalies of $\mathrm{NmF} 2$, and for semiannual and annual amplitude components of $\mathrm{NmF} 2$. The diurnal evolutions of these trends and also of the trends determined without accounting for dependencies on solar activity level are given in Fig. (6). Although trends are hardly significant by any statistical test they exhibit a systematic diurnal evolution. $\mathrm{NmF} 2$ and $\mathrm{NmF} 2$ anomaly trends are almost null during night time and negative from around noon to the early evening. Almost the same can be said for trends of the amplitudes and the amplitude anomalies of the semiannual component. On the contrary, trends for the annual component are always positive and exhibit a rather irregular diurnal pattern. 


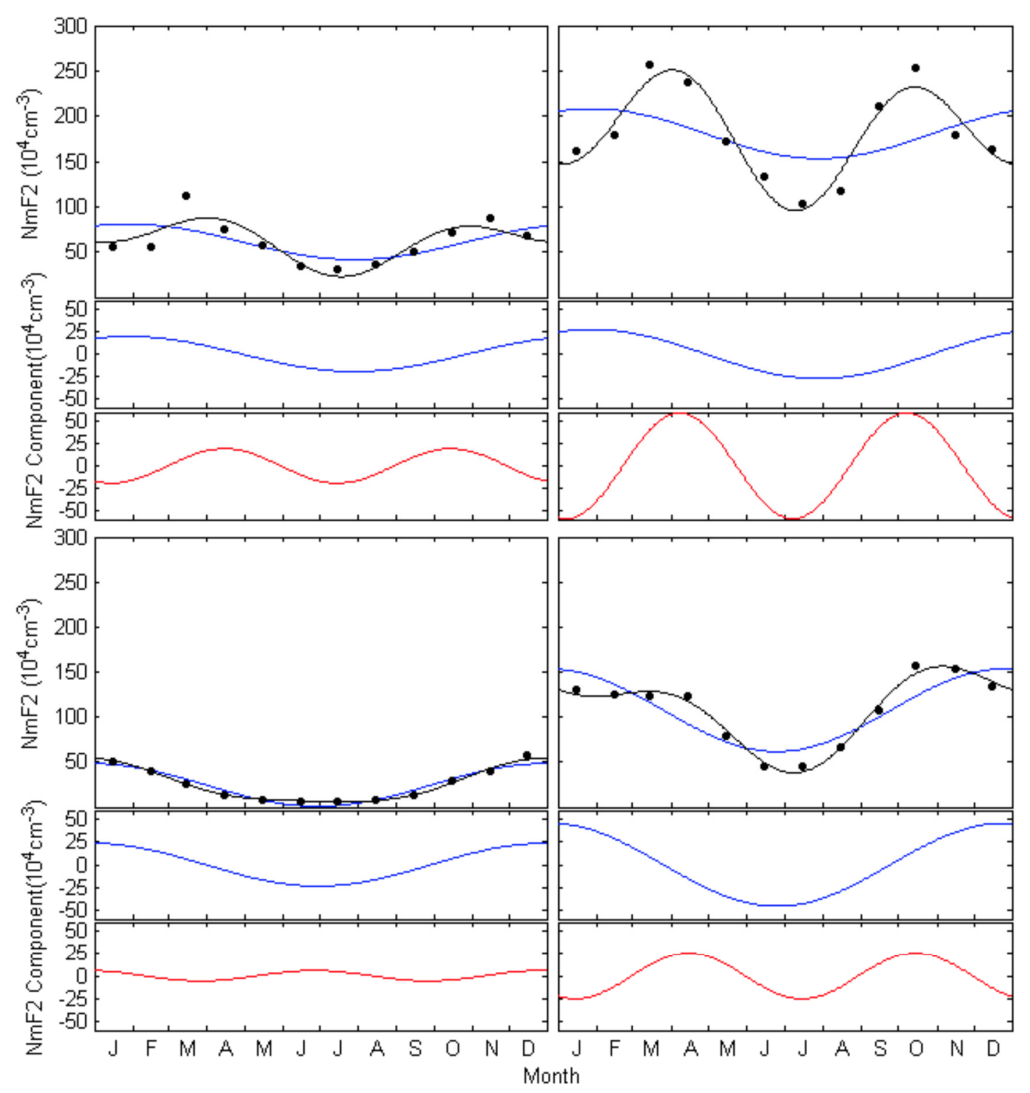

Fig. (2). Sample results of the two components model for the annual evolution of monthly median NmF2 corresponding 1964 (left) and 1980 (right), two years of extreme solar activity levels. (dots) observed values. (blue line) annual component plus annual mean. (black line) annual plus semiannual plus annual mean value. (blue line) annual component. (red line) semiannual component. Top panels: worst cases, 11:00 $\left(75^{\circ} \mathrm{W}\right)$, explained variance (ev) $75 \%$; right, 16:00 $\left(75^{\circ} \mathrm{W}\right)$, ev 90\%. Bottom panels: best cases, 22:00 $\left(75^{\circ} \mathrm{W}\right)$, ev $98 \%$; right, 07:00 $\left(75^{\circ} \mathrm{W}\right)$, ev $99 \%$.

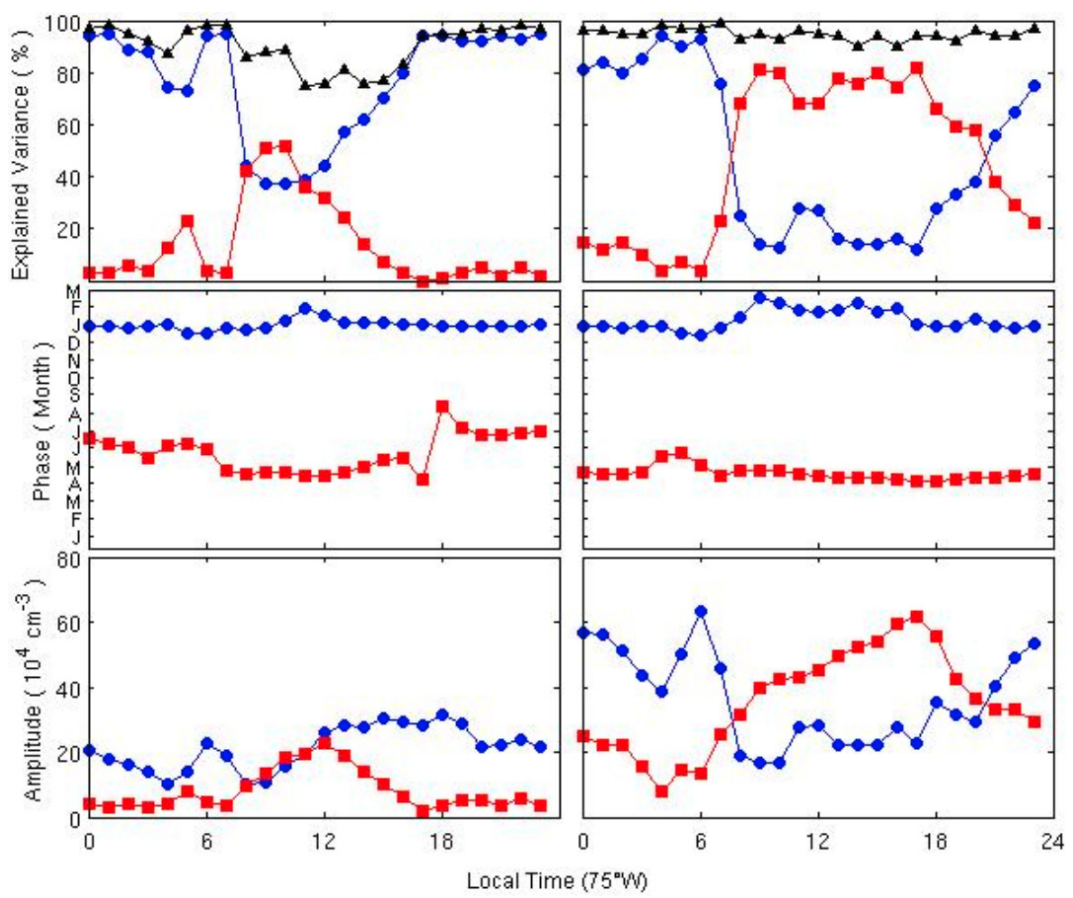

Fig. (3). Diurnal evolution of explained variance (top panels), phase (middle panels) and amplitude (bottom panels) of annual and semiannual components of two model of monthly median NmF2, corresponding to 1964 (left) and 1980 (right), two years of extreme solar activity levels. (black triangles) annual plus semiannual components. (blue circles) annual component. (red squares) semiannual component. 

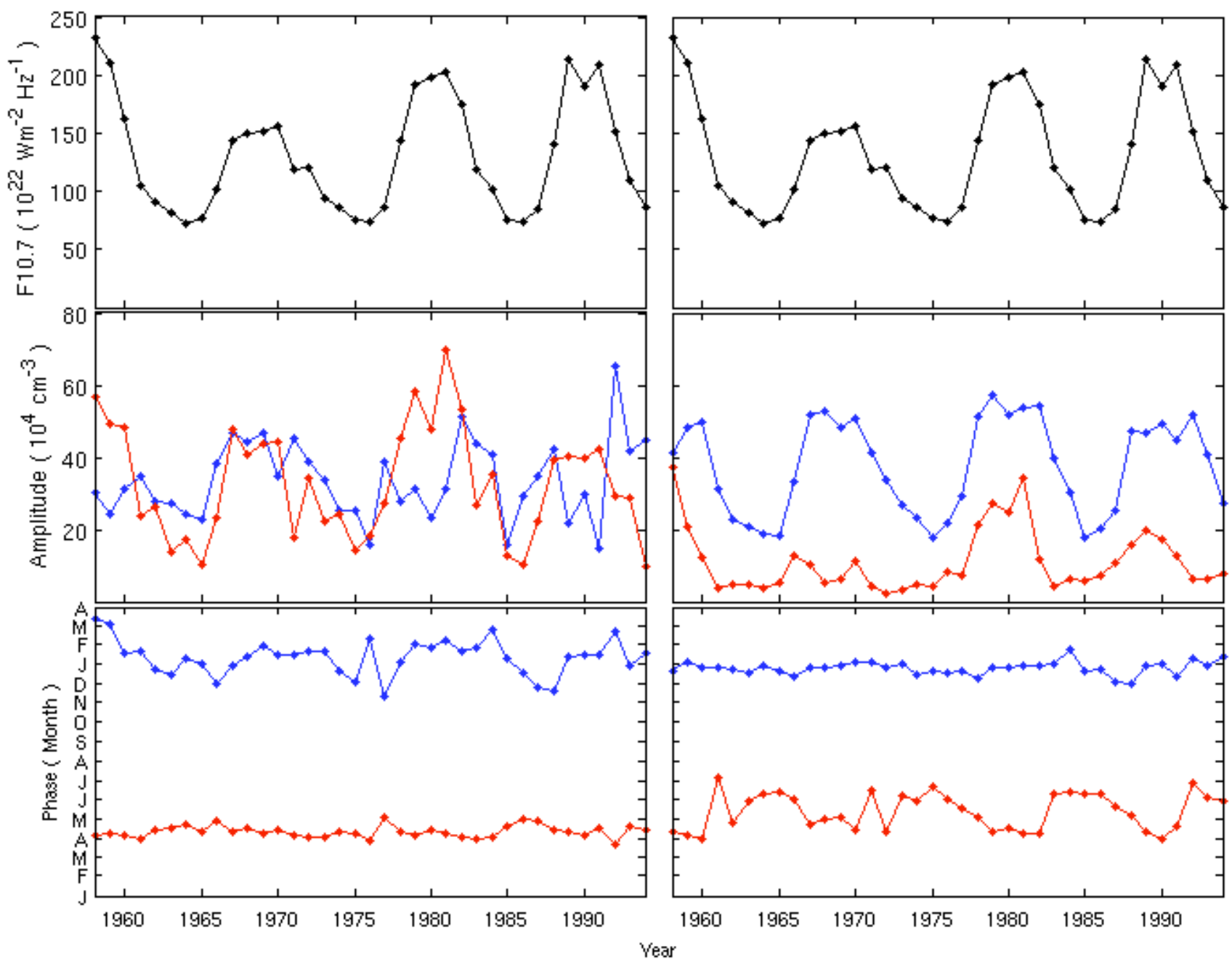

Fig. (4). Yearly mean values of F10.7 (top) and mean values of the amplitudes (middle) and phases (bottom) of the annual (blue) and semiannual (red) components of NmF2. Daytime (10:00 to 15:00) - left. Night time (22:00 to 03:00) - right.

As it would be expected, trends of $\mathrm{NmF} 2$ and $\mathrm{NmF} 2$ anomalies are consistent with the results given by Foppiano et al. [17] for foF2.

\section{DISCUSSION}

Several causes for the semiannual variation of the midlatitude F2-layer have been advanced over the years [13, $14,18]$. The one suggested for midlatitudes (about $50^{\circ}$ geographic latitude) along the so- called "far-from-pole" longitude sector indicates that the relative weight of composition effects, thermospheric wind effects and solar zenith angle changes lead to $\mathrm{NmF} 2$ larger values during equinox than during winter and summer. However, for the lower midlatitudes, as it is the case of Concepción, more study is needed to unfold the relative importance of these changes connected to changes of the strength of the global circulation. Thus, it is even harder to envisage the changes on the semiannual component of $\mathrm{NmF} 2$ which may arise from eventual long-term changes of the global circulation.
Table 1. Geophysical Information of Concepción

\begin{tabular}{|c|c|c|c|c|c|}
\hline \multirow{2}{*}{ Location } & \multicolumn{2}{|c|}{ Coordinates } & \multicolumn{3}{c|}{ Geomagnetic Parameters } \\
\cline { 2 - 6 } & Geographic & Geomagnetic** $^{*}$ L & Inclination & Declination \\
\hline \hline \multirow{2}{*}{ Concepción } & $\begin{array}{c}35.8^{\circ} \mathrm{S} ; \\
287.0^{\circ} \mathrm{E}\end{array}$ & $\begin{array}{c}22.70^{\circ} \mathrm{S} ; \\
359.2^{\circ} \mathrm{E}\end{array}$ & 1.22 & $36.8^{\circ}$ & $8.85^{\circ}$ \\
\hline
\end{tabular}

\section{CONCLUSIONS}

The results presented here suggest that the diurnal patterns of possible trends for $\mathrm{NmF} 2$ and for the amplitude of the semiannual component of $\mathrm{NmF} 2$ are similar, while the one for the annual component is different. It seems reasonable then to particularly look for an explanation of the semiannual component long-term changes when concerned with long-term changes of $\mathrm{NmF} 2$. 

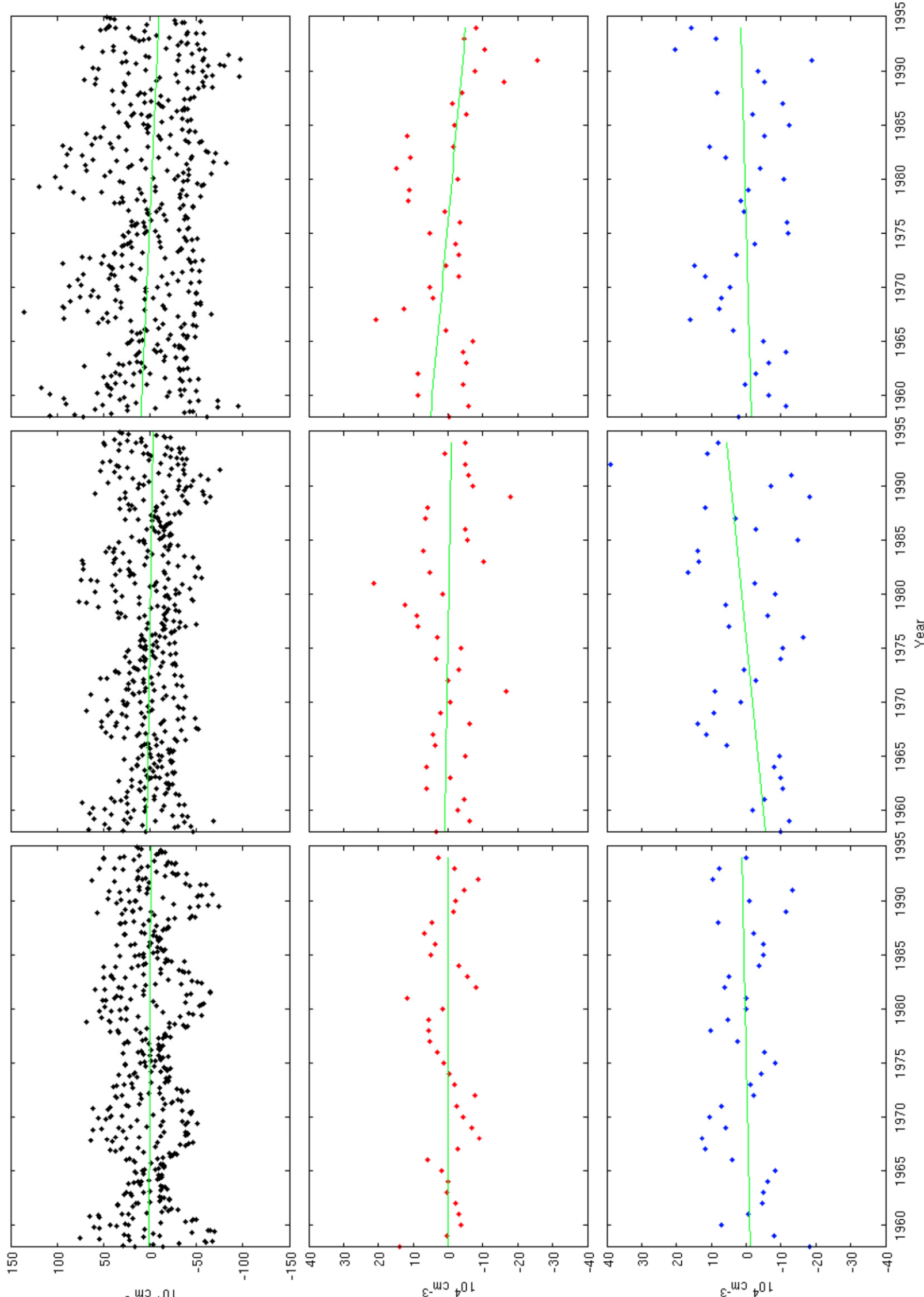

Fig. (5). Anomalies (observed value - F10.7 regression line value) and trends (green lines) of NmF2 (top), semiannual (middle) and annual (bottom) amplitudes for 01:00 (left), 10:00 (centre) and 16:00 (right). 

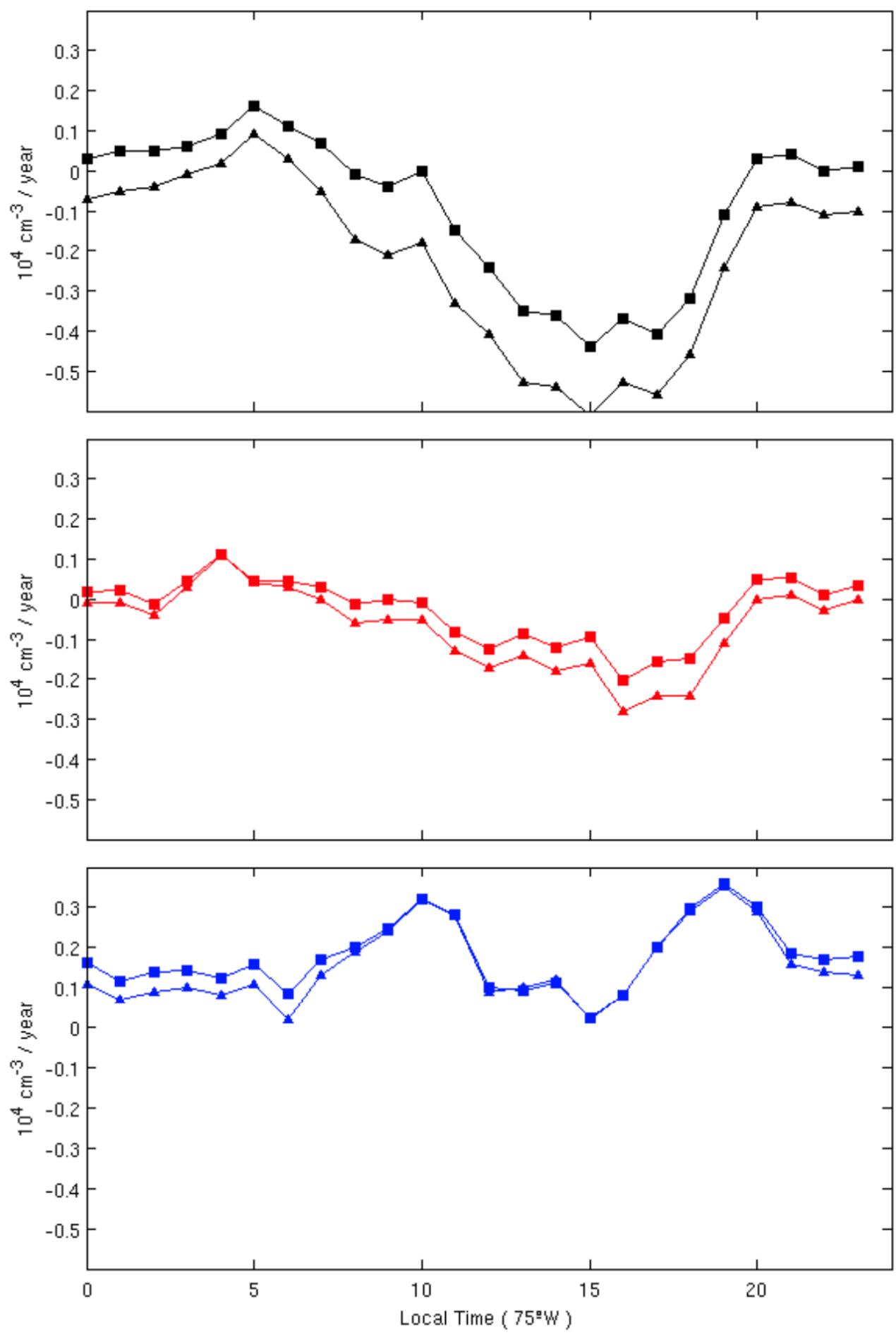

Fig. (6). Diurnal evolutions of trends of anomalies (observed value - F10.7 regression line value, triangles) and of observed values (squares) for $\mathrm{NmF} 2$ (top) and semiannual (middle) and annual (bottom) amplitudes.

\section{REFERENCES}

[1] Cicerone RJ. Greenhouse cooling up high. Nature 1990; 344: 10405 .

[2] Roble RG. and Dickinson RE. How will changes in carbon dioxide and methane modify the mean structure of the mesosphere and lower thermosphere? Geophys Res Lett 1989; 16: 1441-4.

[3] Rishbeth H. A greenhouse effect in the ionosphere? Planet Space Sci 1990; 38: 945-8.

[4] Rishbeth H and Roble RG. Cooling of the upper atmosphere by enhanced greenhouse gases-modelling of thermospheric and ionospheric effects. Planet Space Sci 1992; 40: 1011-26.
Turunen $\mathrm{E}$ and Ulich $\mathrm{T}$. The fourth IAGA-ICMA-CAWSES Workshop 'Long-Term Changes and Trends in the Atmosphere". Ann Geophys 2008; 26: 1171-1171.

[6] Beig G, Lastovicka, J and Langematz U. Long-term changes and solar impacts in the atmosphere-ionosphere system. J Atmos SolarTerr Phys 2009; 71: 1413-4.

[7] Lastovicka J, Akmaev RA and Emmert JT. Long-term changes and trends in the upper atmosphere-An introduction. J Atmos SolarTerr Phys 2009; 71: 1511-3.

[8] Lastovicka J. Global pattern of trends in the upper atmosphere and ionosphere: Recent progress. J Atmos Solar-Terr Phys 2009; $71: 1514-28$. 
[9] Berkner LV, Wells HW and Seaton SL. Characteristics of the upper region of the ionosphere. Terres Magnet Atmos Electric 1936; 41:173-84.

[10] Appleton EV and Naismith R. Some further measurements of upper atmospheric ionization. Proc R Soc Lond A 1935; 150: 685-708.

[11] Yonezawa T. The solar-activity and latitudinal characteristics of the seasonal, non-seasonal and semiannual variations in the peak electron densities of the F2- layer at noon and at midnight in the middle and low latitudes. J Atmos Terr Phys 1971; 33: 889-907.

[12] Yonezawa $\mathrm{T}$ and Arima $\mathrm{Y}$. On the seasonal and non-seasonal annual variations and the semiannual variation in the noon and midnight electron densities of the F2-layer in middle latitudes. J Radio Res Lab 1959; 6: 293-309.

[13] Rishbeth H, Müller-Wodarg ICF, Zou L, et al. Annual and semiannual variations in the ionospheric F2-layer: II. Physical discussion. Ann Geophys 2000; 18: 945-56.
[14] Zou L, Rishbeth H, Müller-Wodarg ICF, et al. Annual and semiannual variations in the ionospheric F2-layer: I. Modelling. Ann Geophys 2000; 18: 927-44.

[15] Ma R, Xu J, Liao H. The features and a possible mechanism of semiannual variation in the peak electron density of the low latitude F2 layer. J Atmos Solar-Terr Phys 2003; 65: 47-57.

[16] Yu T, Wan W, Liu L, Zhao B. Global scale annual and semiannual variations of daytime $\mathrm{NmF} 2$ in the high solar activity years. J Atmos Solar-Terr Phys 2004; 66: 1691-701.

[17] Foppiano AJ, Cid L, Jara V. Ionospheric long-term trends in South American mid-latitudes. J Atmos Solar-Terr Phys 1999; 61: 71723.

[18] Rishbeth H. How the thermospheric circulation affects the ionospheric F2-layer. J Atmos Solar-Terr Phys 1998; 60: 1385-402.

Received: January 8, 2010

Revised: July 8, 2010

Accepted: July 19, 2010

(C) Bravo et al.; Licensee Bentham Open.

This is an open access article licensed under the terms of the Creative Commons Attribution Non-Commercial License (http: //creativecommons.org/licenses/by$\mathrm{nc} / 3.0 /$ ) which permits unrestricted, non-commercial use, distribution and reproduction in any medium, provided the work is properly cited. 